Original article

\title{
Psychological Assessment in Children with Chronic Kidney Disease on Regular Hemodialysis.
}

\author{
Wesam E. Afifi' ${ }^{1}$, Soha A. El gendy ${ }^{1}$, Rashad Abd El Hakim ${ }^{1}$, \\ Shweikar El Bakry ${ }^{2}$, Ezzat K. Amin ${ }^{3}$, Amany A. Elzakzouk ${ }^{4}$ \\ 1. Department of Pediatrics, Pediatric Nephrology Unit, Faculty of Medicine, Benha University, Egypt. \\ 2. Department of Neuropsychiatry, Faculty of Medicine, Benha University, Egypt. \\ 3. Department of Pediatrics, Pediatric Nephrology Unit, Zagazig University, Egypt. \\ 4. Department of Pediatrics, El Shiekh Zayed Specialized Hospital, Ministry of Health, Cairo, Egypt.
}

Abstract

Introduction: Interestingly, health care professionals have the tendency to focus on the biological dimension of the disease or other technical issues related to hemodialysis machine and usually underestimate symptoms from mental sphere. Encouraging patients to express their feelings and addressing their psychological needs may be an essential measure to confront with this debilitating disease. Aim of Study: The objective of our study were to assess the presence, possible factors related and consequences of psychological disorders in children with CKD on regular hemodialysis.

Methods: This study was cross sectional study which carried out in nephrology unit of the pediatric department during the period from February 2019 to December 2019.It were comprised (141) children with CKD on regular hemodialysis of both sexes after obtaining informed consent from children's parents. All patients were subjected to history (age, sex, residence, birth order, level of education, socioeconomic status), examination and specific investigations.

Results: This study showed that, a male predominance. Regarding anxiety grade, mild were 18 (12.8\%), moderate were $54(38.3 \%)$ and severe were 69 (48.9\%). Regarding depression grade, mild were 50 $(35.5 \%)$, moderate were $54(38.3 \%)$, and severe were $19(13.5 \%)$ while no depression was found among $18(12.8 \%)$. There were statistically significant positive correlations between anxiety score and duration of dialysis. There were statistically significant positive correlations between anxiety score and depression score.

Conclusion: Frequency of anxiety and depression is high in CKD Patients. There were statistically significant positive correlations between anxiety score and depression score.

Key words: - CKD- hemodialysis - Psychological disorders.

\section{Corresponding Author Amany A. Elzakzouk}

Address: Department of Pediatrics, El Shiekh Zayed Specialized Hospital, Ministry of Health, Cairo, Egypt.

Email: amany_abdelall88@yahoo.com

geget: The Journal of the Egyptian Society of Pediatric Nephrology and Transplantation (ESPNT)

geget https://geget.journals.ekb.eg/

Published by ESPNT http://espnt.net/

Cohosted by Egyptian Knowledge Bank https://www.ekb.eg 


\section{Introduction}

Anxiety and depression are common psychiatric disorders among patients undergoing hemodialysis (HD). Several factors seem to trigger anxiety and depression in hemodialysis patients such as co-morbidities, frequent hospitalizations, chronic pain, sleep disturbances, chronic inflammation, increased fatigue, uremia, failure of family support restrictions in daily life, non-compliance to therapeutic regimen including restrictions in diet and fluids, and dependency upon treatment and health professionals [1].

Interestingly, health care professionals have the tendency to focus on the biological dimension of the disease or other technical issues related to hemodialysis machine and usually underestimate symptoms from mental sphere. Encouraging patients to express their feelings and addressing their psychological needs may be an essential measure to confront with this debilitating disease [2].

Consultation-liaison psychiatry in renal medicine provides a unique experience for the psychiatrist as it provides the opportunity to work with a specialist multi-disciplinary team managing patients with chronic and complex physical problems in in-patient and out-patient settings. Any chronic illness is a potential life crisis for patients and their family. Chronic kidney disease (CKD) is emerging as an important chronic disease globally [3].

Advances in medical care, including improvements in dialysis and transplantation, have increased the survival rates for children with chronic renal failure (CRF). This long survival increases the opportunities for the development of psychiatric morbidity among these children [4].

\section{Aim of the study}

The objective of our study were to assess the presence, possible factors related and consequences of psychological disorders in children with CKD on regular hemodialysis.

\section{Methods}

This study was cross sectional study which carried out in nephrology unit of the pediatric department from February 2019 to December 2019. It were comprised (141) children with CKD on regular hemodialysis of both sexes after obtaining informed written consent from children's parents.

The study were under the following inclusion and exclusion criteria; Inclusion criteria: children with CKD on regular hemodialysis, both sexes, children age from 6 years up to 18 years. Exclusion criteria: children suffering from other chronic diseases, children with neurological diseases, children diagnosed with mental disorders before starting hemodialysis.

All patients included in this study were subjected to: full history taking in form of; Personal history (age, sex, residence, birth order, level of education, socioeconomic status). Present history (cause \& duration of the disease, duration of dialysis session, frequency of dialysis, any complains before \& after dialysis session, complications of hemodialysis as hypotension, infection \& bleeding, used medications. Daily physical activities as:

(a) Nutritional habits, e.g., appetite 
change in desire or amounts, number of meals per day, and preferred restricted food and types of food prepared for the child at home.

(b)Sleeping patterns, e.g., place of sleeping, number of hours of sleep per day, and naps and sleep problems. (c) Exercise habits. (d) School attendance and achievements

Clinical examination: General examination: vital signs, anthropometric measurements (weight, height, body mass index), face, color (pallor, jaundice, cyanosis), limb edema and skin rash, chest, heart, neurological and Local abdominal examination. Routine laboratory investigations (CBC, serum electrolytes ( $\mathrm{Na}, \mathrm{K}, \mathrm{Ca}, \mathrm{Po} 4)$, kidney function tests and liver function tests).

\section{Self-reporting scales:}

\section{(A) Children anxiety scale [5]:}

o This scale consists of 42 items to measure anxiety in children which is considered a group of symptoms which can be classified into 3 groups physiological, behavioral and verbal measures.

o 11 items were added as lie scale to ensure the reliability of answers of these children.

o If the patient's answers more than 3 degrees on lie scale, this patient is excluded from the study.

o The total number of items in the scale are 53 and each item consists of one

o Statement which has two answers yes or no.

o If the answer is Yes $\rightarrow$ score 1

0 lf the answer is No $\rightarrow$ score 0

o Total score ranges from $(0-53)$

o According to their scores, they were classified into mild, moderate and severe degree of anxiety as shown in (Table 1).
Past history (complications of hemodialysis as hypotension, infection and bleeding, other diseases and operations, previous medications). Family history (similar conditions, consanguinity, psychiatric conditions, attitude of family, accompanying family member to dialysis session).

\section{(B) Children depression inventory scale (CDI) [6]:}

o This scale is designed to assess mood disturbance, ability of enjoyment, growth functions, self-esteem and behavior with others.

o The scale includes 27 items; each item consists of 3 choices of answers and the patient should choose one.

o According to the severity, the degrees ranges from $0-2$ as follows:

No symptoms $=0$, Mild to moderate $=1$, Severe symptoms $=2$, Total score ranges from (0-54), as shown in (Table 2).

\section{Procedures:}

o This questionnaire was applied individually.

o Every child had given 2 questionnaire sheets (one for anxiety \& the other for depression) \& a pen.

o The questionnaire was explained for all children \& how to answer it after having their agreement to share in this study.

o $70 \%$ (98 children) answered the questionnaire by themselves.

o $30 \%$ (43 children) could not read well so $\mathrm{i}$ asked them and wrote their answers in the sheet.

o The average time for application of the questionnaire differs according to level of education of children and their ability to read and understand the questions.

o According to anxiety test it took about 
15 to 40 minutes.

o According to depression test it took about 20 to 45 minutes.

o 7 children did not complete the tests because they had finished their sessions and wanted to leave.

o 5 children did not complete the tests because they had complications during dialysis session as hypotension.

o 11 children had more than 3 in lie scale so they were excluded from the study.

o 10 children refused to share because they were tired and not interested in the study.

\section{Statistical analysis}

The collected data was revised, coded, tabulated and introduced to a PC using Statistical package for Social Science
(IBM Corp. Released 2011. IBM SPSS Statistics for Windows, Version 24.0. Armonk, NY: IBM Corp.). Data were presented and suitable analysis was done according to the type of data obtained for each parameter. Mean, Standard deviation ( \pm SD) for parametric numerical data, while Median and range for nonparametric numerical data. Shapiro test was done to test the normality of data distribution. Significant data was considered to be nonparametric. Student $\mathrm{T}$ Test was used to assess the statistical significance of the difference between two study group means. Chi-Square test was used to examine the relationship between two qualitative variables. Correlation analysis: To assess the strength of association between two quantitative variables.

Table 1 : Children anxiety scale

\begin{tabular}{|c|c|}
\hline Children anxiety score & Children anxiety status \\
\hline$<18$ & Mild \\
\hline $19-28$ & Moderate \\
\hline$>29$ & Severe \\
\hline
\end{tabular}

Table 2 : Children depression inventory scale

\begin{tabular}{|c|c|c|}
\hline Depression & Gender & Depression status \\
\hline $0-9$ & & Normal \\
\hline $9-14$ & Male & Mild \\
\hline $9-16$ & Female & Mild \\
\hline $14-18$ & Male & Moderate \\
\hline $16-22$ & Female & Severe \\
\hline$>18$ & Male & Severe \\
\hline$>22$ & Female & \\
\hline
\end{tabular}

\section{Results}

This cross sectional study was carried out from February 2019 to December 2019. It comprised 141 children with CKD on regular hemodialysis of both sexes after obtaining an informed consent from the children care givers. Ages of the children included in this study ranged from 7 to 18 years and the study shows male predominance as $(51.8 \%)$ were males. Most of the children were accompanied by their mothers $(85.1 \%)$ during the dialysis sessions as shown in (Table 3).

Regarding anthropometric measurement $<3$ rd percentile of weight and height were the most frequent as 
shown in (Table 4). This study shows that unknown causes were the most frequent $(35.4 \%)$ and trauma was the least frequent $(0.7 \%)$ cause of renal failure as shown in (Table 5).

Although some patients had abnormal electrolyte levels (calcium, sodium, potassium and phosphorus) the mean values of these electrolytes were within normal ranges. On the other hand the mean level of creatinine and urea were high but the mean level of hemoglobin was low because most of patients were anemic (Table 6).

Among the studied cases sever anxiety was the commonest (48.95) as shown in (Table 7). Regarding depression (12.8\%) of cases were normal, $(35.5 \%)$ were mild, $(38.3 \%)$ were moderate, $(13.5 \%)$ were sever as shown in (Table 8). This study shows that mean value of anxiety score was significantly higher among Cases with depression than those without (28.02, 17.72 respectively) $p=0.000$ as shown in (Figure 1). As shown in (Figure 2) there is a high significance correlation between duration of dialysis $\&$ depression grade.
This study shows absolute significant correlations between depression score and (age, weight, height, ca, potassium, po4, urea and duration of dialysis). There were statistically significant negative correlations between depression score \& (height). There were no statistically significant correlations between depression score $\&$ other numerical data as shown in (Table 9).

This study also shows statistically significant positive correlations between anxiety score \& (age, weight, potassium, po4, duration of dialysis \& depression score). There were statistically significant negative correlations between anxiety score \& (height). There were no statistically significant correlations between anxiety score \& other numerical data as shown in (Table 10).

Table 3 : Demographic data of children undergoing renal dialysis.

\begin{tabular}{|c|c|c|c|}
\hline \multirow{2}{*}{ Age (years) } & Range & Mean \pm SD \\
\cline { 3 - 4 } & & $\mathbf{7 . 0}-\mathbf{1 8 . 0}$ & $\mathbf{1 3 . 1 3} \pm \mathbf{3 . 2 8}$ \\
\cline { 3 - 4 } & & No. (141) & \% \\
\hline \multirow{3}{*}{ Age Categories } & $\mathbf{7 - 1 0}$ & 38 & 27.0 \\
\cline { 2 - 4 } & $\mathbf{1 0}-<\mathbf{1 4}$ & 37 & 26.2 \\
\cline { 2 - 4 } & $\mathbf{1 1 4}$ & 66 & 46.8 \\
\hline \multirow{3}{*}{ Sex } & Male & 73 & 51.8 \\
\cline { 2 - 4 } & Female & 68 & 48.2 \\
\hline \multirow{3}{*}{ Residence } & Urban & 80 & 56.7 \\
\cline { 2 - 4 } & Rural & 61 & 43.3 \\
\hline \multirow{3}{*}{ Gradeol Enrollment } & Enrolled & 122 & 86.5 \\
\cline { 2 - 4 } & Not enrolled & 19 & 13.5 \\
\hline \multirow{3}{*}{ Accompanying Person } & Primary & 47 & 33.3 \\
\cline { 2 - 4 } & Preparatory & 45 & 31.9 \\
\cline { 2 - 4 } & Secondary & 30 & 21.2 \\
\cline { 2 - 4 } & Mother & 120 & 85.1 \\
\cline { 2 - 4 } & Grand ma & 2 & 1.4 \\
\cline { 2 - 4 } & Father & 3 & 2.1 \\
\cline { 2 - 4 } & No one & 15 & 10.6 \\
\cline { 2 - 4 } & Sister & 1 & 0.7 \\
\hline
\end{tabular}


Table 4 : Anthropometric measurement among the studied cases.

\begin{tabular}{|c|c|c|c|}
\hline & & Range & Mean \pm SD \\
\hline \multicolumn{2}{|c|}{ Weight(kg) } & $18-100$ & $33.37 \pm 13.47$ \\
\hline \multicolumn{2}{|c|}{ Height(cm.) } & $90-170$ & $121.08 \pm 21.579$ \\
\hline & & No. & $\%$ \\
\hline \multirow[t]{12}{*}{ Weight Percentile } & $<3$ & 70 & 49.6 \\
\hline & $>97$ & 2 & 1.4 \\
\hline & 10 & 14 & 9.9 \\
\hline & 10--25 & 18 & 12.8 \\
\hline & 25 & 4 & 2.8 \\
\hline & $25-50$ & 4 & 2.8 \\
\hline & 3 & 9 & 6.4 \\
\hline & $3--5$ & 4 & 2.8 \\
\hline & 5 & 7 & 5.0 \\
\hline & $5--10$ & 5 & 3.5 \\
\hline & $50-75$ & 3 & 2.1 \\
\hline & 97 & 1 & .7 \\
\hline \multirow[t]{9}{*}{ Height Percentile } & $<3$ & 61 & 43.3 \\
\hline & 10 & 15 & 10.6 \\
\hline & 10--25 & 9 & 6.4 \\
\hline & 25 & 10 & 7.1 \\
\hline & $25-50$ & 1 & .7 \\
\hline & 3 & 14 & 9.9 \\
\hline & 5 & 17 & 12.1 \\
\hline & $5--10$ & 6 & 4.3 \\
\hline & 50 & 8 & 5.7 \\
\hline
\end{tabular}

Table 5 : Cause of renal failure among the studied cases.

\begin{tabular}{|l|l|c|c|}
\hline \multicolumn{2}{|c|}{} & No. & \% \\
\hline \multirow{4}{*}{ Cause of renal failure } & Unknown & 50 & 35.4 \\
\cline { 2 - 4 } & Congenital & 31 & 21.9 \\
\cline { 2 - 4 } & Metabolic & 6 & 4.3 \\
\cline { 2 - 4 } & HUS & 7 & 4.9 \\
\cline { 2 - 4 } & Glomerulonephritis & 6 & 4.3 \\
\cline { 2 - 4 } & Nephrotic Syndrome & 11 & 7.8 \\
\cline { 2 - 4 } & Nephrotoxic Drugs & 2 & 1.4 \\
\cline { 2 - 4 } & Obstructive Uropathy & 22 & 15.6 \\
\cline { 2 - 4 } & Trauma & \multicolumn{2}{|c|}{0.7} \\
\cline { 2 - 4 } & Vaculitis & 5 & 3.5 \\
\hline
\end{tabular}

Table 6 : Laboratory investigation among the studied cases.

\begin{tabular}{|c|c|c|}
\hline & Range & Mean \pm SD \\
\hline Hemoglobin (g/dL) & $6.5-15.3$ & $10.07 \pm 1.55$ \\
\hline Calcium (mg/dL) & $3.7-17.0$ & $8.51 \pm 2.19$ \\
\hline Sodium (mEq/L) & $125.0-160.0$ & $137.64 \pm 4.42$ \\
\hline Potassium (mmol/L) & $2.3-8.5$ & $5.88 \pm 1.02$ \\
\hline Phosphorus (mg/dL) & $1.2-11.0$ & $4.81 \pm 2.11$ \\
\hline Urea (mg/dL) & $4.9-189.0$ & $76.49 \pm 31.19$ \\
\hline Creatinine (mg/dL) & $0.9-14.8$ & $7.07 \pm 2.17$ \\
\hline
\end{tabular}


Table 7 : Anxiety score among the studied cases.

\begin{tabular}{|c|c|c|c|}
\hline & & Range & Mean \pm SD \\
\hline \multicolumn{2}{|c|}{ Anxiety Score } & $9-39$ & $26.71 \pm 7.85$ \\
\hline & & No. & $\%$ \\
\hline \multirow{3}{*}{ Anxiety Grade } & Mild & 18 & 12.8 \\
\hline & Moderate & 54 & 38.3 \\
\hline & Severe & 69 & 48.9 \\
\hline
\end{tabular}

Table 8 : Depression grade among the studied cases.

\begin{tabular}{|c|l|c|c|}
\hline \multicolumn{2}{|c|}{} & Range & Mean \pm SD \\
\hline \multicolumn{2}{|c|}{ Depression Score } & $6-29$ & $15.33 \pm 5.53$ \\
\hline \multirow{3}{*}{ Depression Grade } & Normal & No. & \% \\
\cline { 2 - 4 } & Mild & 18 & 12.8 \\
\cline { 2 - 4 } & Moderate & 50 & 35.5 \\
\cline { 2 - 4 } & Severe & 54 & 38.3 \\
\hline
\end{tabular}

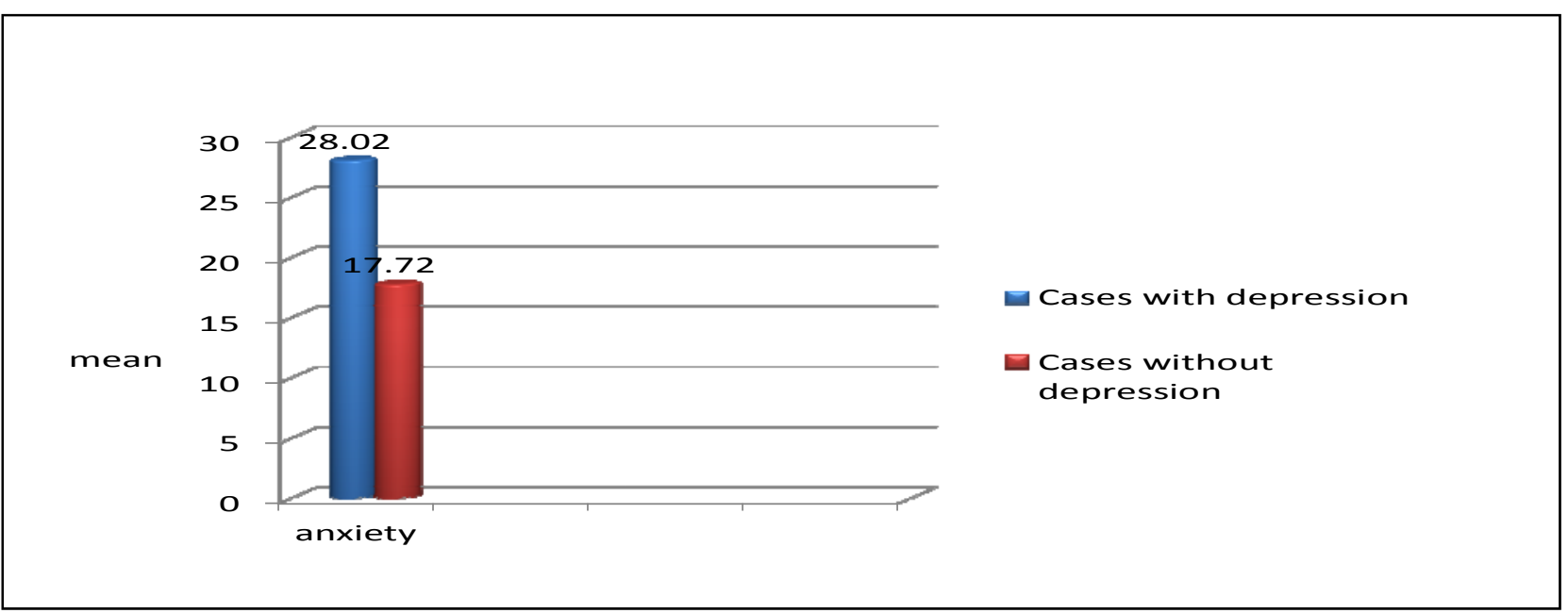

Figure 1 Comparison between Cases with depression \& Cases without depression regarding anxiety score.

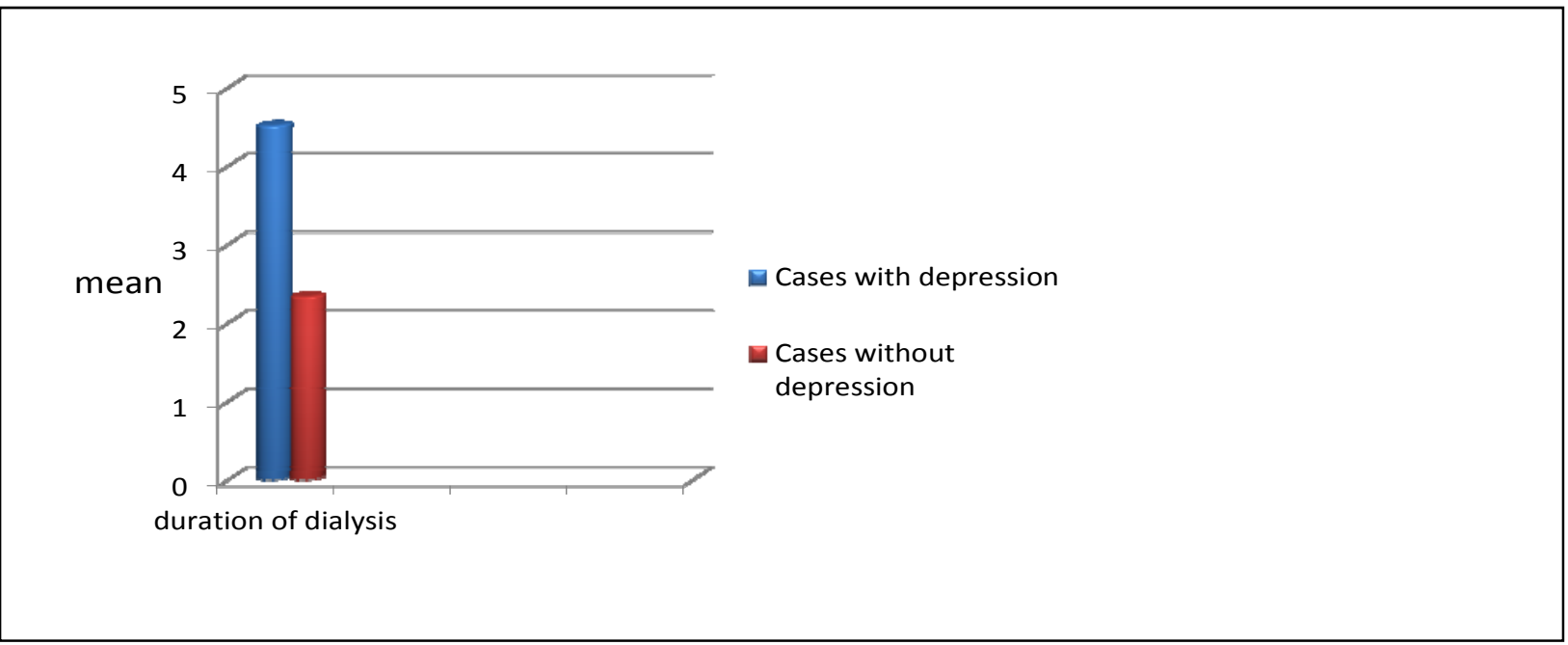

Figure 2 Comparison between Cases with depression and Cases without depression regarding duration of dialysis. 
Table 9 : Correlation between depression score and other numerical data.

\begin{tabular}{|c|c|c|}
\hline Correlation & \multicolumn{2}{|c|}{ Pearson's correlation } \\
\cline { 2 - 3 } Age & $\mathbf{r}$ & $\mathbf{p}$ \\
\hline Weight & .347 & $0.000^{* *}$ \\
\hline Height & .352 & $0.000^{* *}$ \\
\hline Hemoglobin & -.222 & $0.008^{* *}$ \\
\hline Calcium & .033 & 0.694 \\
\hline Sodium & -.238 & $0.004^{* *}$ \\
\hline Potassium & -.016 & 0.854 \\
\hline Phosphorous & .055 & $0.017^{*}$ \\
\hline Urea & 126 & $0.013^{*}$ \\
\hline Creatinine & .209 & $0.013^{*}$ \\
\hline Duration Of Dialysis & .157 & 0.062 \\
\hline Duration Of Session & .419 & $0.000^{* *}$ \\
\hline
\end{tabular}

Table 10 : Correlation between anxiety score and other numerical data.

\begin{tabular}{|c|c|c|}
\hline Correlation & \multicolumn{2}{|c|}{ Pearson's correlation } \\
\cline { 2 - 3 } & $\mathbf{r}$ & $\mathbf{p}$ \\
\hline Age & .309 & $0.000^{* *}$ \\
\hline Weight & .311 & $0.000^{* *}$ \\
\hline Height & .229 & $0.006^{* *}$ \\
\hline Calcium & -.005 & 0.949 \\
\hline Sodium & -.087 & 0.306 \\
\hline Potassium & .031 & 0.716 \\
\hline Phosphorous & .077 & $0.036^{*}$ \\
\hline Urea & .202 & $0.016^{*}$ \\
\hline Creatinine & -.061 & 0.473 \\
\hline Duration Of Dialysis & .045 & 0.598 \\
\hline Duration Of Session /Hour & .446 & $0.000^{* *}$ \\
\hline Depression Score & -.007 & 0.939 \\
\hline
\end{tabular}

* Significant ** high significant

\section{Discussion}

This study showed a male predominance $(51.8 \%)$ and females $(48.2 \%)$. Our results are in agreement with [7] who found the incidence and prevalence of CKD is greater in males than females because of the higher frequency of congenital abnormalities of the kidney and urinary tract (CAKUT) in males.

In our work, growth impairment is common among the studied cases as it shows that weight percentile $<3$ (49.65) and height percentile $<3$ (43.4\%). Our results are in agreement with [8] who found that, growth impairment is a common and perhaps the most visible complication of CKD in children. This finding was in accordance with the study of [9] who found, height was the most severely affected anthropometric parameter in children with CKD on regular HD (92\%). On the other hand, data from developed countries generally show a less severe effect on height, and the literature shows that only $36.6 \%$, $47.0 \%$ and $43 \%$ among children with 
chronic renal insufficiency, dialysis and transplantation, respectively, have short stature [10].

In the current study, the causes of renal failure among the studied cases, unknown causes were the most frequent (35.4\%) followed by congenital causes $(21.9 \%)$. This is in concordance with the results from [11], where unknown causes, nephritis, congenital anomalies, posterior urethral valves (PUV) and stones were the most common causes of CRF in Egyptian children.

Also the results are in agreement with [9] who aimed to assess the nutritional status of Egyptian children with end-stage renal disease (ESRD) on regular hemodialysis (HD). Their study included 50 Egyptian children with ESRD on regular HD, following-up at the Pediatric Nephrology unit, Cairo University. They found that urological disorders, followed by hypoplastic, unknown and glomerular disease, were the most frequent causes of CKD. But the results are in disagreement with [12] who revealed that, primary causes of CKD in children significantly differ from those that are responsible for the adult onset of the disease. In fact, the main etiologic factors of CKD in children are represented by congenital abnormalities of the kidney and urinary tract (CAKUT).

This study showed that, laboratory investigations found that most patients enrolled in the study group had some degree of anemia. A recent review of renal anemia concluded that anemia in CKD is due to two mechanisms; (a) reduced production of erythropoietin in the kidney and (b) due to shortened red cell survival [13].

This study demonstrated regarding to anxiety score among all studied cases ranged between 9 and 39 with Mean \pm SD was $26.71 \pm 7.85$, Regarding anxiety grade, mild were $18(12.8 \%)$, moderate were $54(38.3 \%)$ and sever were 69 $(48.9 \%)$.

The increased level of anxiety-state among patients on HD may be explained by the specificity of this renal replacement therapy. The hemodialysis sessions in themselves are commonly associated with acute feelings of anxiety. According to the studies by [14] anxiety among hemodialyzed patients was triggered when patients arrived for HD treatment, when they heard alarm and machine sound or when new staff connected the patient to dialysis machine. These observations suggest that the modification in the conduct of hemodialysis may reduce some anxiety during the dialysis treatment.

Our results are in agreement with [15] who found that, there was a high prevalence rate of anxiety among hemodialysis patients, majority of pediatric patients undergoing hemodialysis were severely anxious. They found anxiety (severe ' $65 \%$ ', moderate '27.5\%', and mild '7.5 \%'). Notably, anxiety is a common psychological problem that may emerge during the initial course of dialysis. Thus, it is important to identify anxiety symptoms in dialysis patients. [16].

Our results are in agreement with [17] who found anxiety were present in 111 $(71.2 \%)$ of dialysis patients. Yet our results were in disagreement with the results of [18] who followed up 159 patients with $\mathrm{CKD}$, and only 50 patients (31.8\%) had anxiety. The importance of anxiety may have been underestimated in HD patients. Notably, anxiety is a common psychological problem that may 
emerge during the initial course of dialysis. Thus, it is important to identify anxiety symptoms in dialysis patients [16].

This study showed that, regarding to depression score among all studied cases ranged between 6 and 29 with Mean +SD was $15.33 \pm 5.53$, Regarding depression grade, mild were $50(35.5 \%)$, moderate were $54(38.3 \%)$, and sever were 19 $(13.5 \%)$ while no depression was found among $18 \quad(12.8 \%)$. The exact pathogenesis of depression is still unknown but the genetic and environmental factors are believed to be important [19].

The higher prevalence of depression in chronic kidney disease (CKD) patients may be related to higher prevalence of comorbid chronic diseases, complications of anemia and vitamin B 12 deficiency, genetic factors, greater mental stress, and hyperinflammatory status. The presence of uremic products may also contribute to depression [20]. Our results are in disagreement with [15] who found prevalence of depression (severe '95\%' and moderate ' $5 \%$ ').

Our results are in agreement also with [21] who found that, about $44 \%$ of the patients were found to have depression and with [17] who found depression were present in $113(72.4 \%)$ of patients on hemodialysis. [22] had a close resemblance with the current data as they proved that depression is present in 75$83.8 \%$ of children on hemodialysis. However in some studies, frequency of depression was found to be lower (48.8$57.3 \%$ ) [23]. Prevalence of depression was found lower than that of the study carried out by [24] (66\%); [23] (57\%); [25] (52.5\%); [26] (47\%). Over 50\% of the patients were found depressed according to the study carried out by [27].

This study demonstrated that, there were statistically significant positive correlations between anxiety score and duration of dialysis. A study by [28] who find significant correlation between anxiety and the duration of HD resembles our results. This is in accordance also with the study by [29] who found the change in anxiety as a state correlated with the disease duration, duration of dialysis.

In the current study, there were statistically significant positive correlations between anxiety score and depression score. Our results are in agreement with [15] who found there was highly significant positive correlation between anxiety and depression. This is in accordance with the study by [29] who found the change in anxiety was highly significant positive correlated to depression and with [30] who they found that, there were statistically significant positive correlations between anxiety score and depression score.

The current findings concerning the association between anxiety and depression among patients seems to be consistent with literature. Several explanations may account for this observed association. For instance, an untreated anxiety may lead to depression, and may have a negative effect on interpersonal relationships, thus leading to failure in adapting to demands of this chronic treatment [1].

\section{Conclusion}

Frequency of anxiety and depression is high in CKD Patients. There were statistically significant positive 
correlations between anxiety score and depression score. Many factors contribute to increased anxiety and depression among theses patients as complications of hemodialysis, lack of friends, being refused from society, inability to live a normal life as other children, loss of hope to be cured and fear of deathAlthough frequency of psychological problems among children with CKD, there is no psychological follow up for these patient.

\section{References}

1. Gerogianni, G., Polikandrioti, M., Babatsikou, F., Zyga, S., Alikari, V., Vasilopoulos, G., Gerogianni, S., \& Grapsa, E. Anxiety-Depression of Dialysis Patients and Their Caregivers. Medicina (Kaunas, Lithuania) 2019; 55(5), p168. https://doi.org/10.3390/medicina55050168

2. Vasilopoulou C., Bourtsi E., Giaple S., Koutelekos I., Theofilou P., Polikandrioti M. The Impact of Anxiety and Depression on the Quality of Life of Hemodialysis Patients. Glob. J. Health Sci 2015; 8: pp45-55.

3. Goyal E, Chaudhury S, and Saldanha D. Psychiatric comorbidity in patients undergoing hemodialysis. Ind Psychiatry J [serial online] 2018 [cited 2019 Aug 29]; 27:206-12.

4. Nazar, C. M., Bojerenu, M. M., Safdar, M., Ahmed, A., Akhtar, M. H., and Kindratt, T. B. Efficacy of dietary interventions in end-stage renal disease patients; a systematic review. Journal of nephropharmacology 2015; 5(1), pp28-40.

5. Beblawi V. : Anxiety for children. The Anglo Egyptian Library, Cairo, Egypt 1987.

6. Ghareeb, G. A., \& Beshai, J. A. Arabic Version of the Children's Depression Inventory: Reliability and Validity. Journal of Clinical Child Psychology1989; 18(4), pp323-326.

7. Harambat J, van Stralen KJ, Kim JJ et al. Epidemiology of chronic kidney disease in children. Pediatr Nephrol 2012; 27: pp363373.

8. Seikaly MG, Salhab N, Gipson D, Yiu V and Stablein D. Stature in children with chronic kidney disease: analysis of NAPRTCS database. Pediatr Nephrol2016; 21(6): pp7939.

9. Lotfy HM, Sabry SM, Ghobrial EE, Abed SA. The effect of regular hemodialysis on the nutritional status of children with end-stage renal disease. Saudi J Kidney Dis Transpl 2015; 26: pp263-70.

10. National Kidney Foundation. Kidney Disease Outcome Quality Initiative (NKF$\mathrm{K} / \mathrm{DOQI}$ ) Clinical practice guideline for nutrition in CRF. Am J Kidney Dis 2000; 35 (Suppl 2): S1-40.

11. Safouh H. A profile of renal diseases in Egyptian children. 1st pan Arab Pediatric Nephrology Conference, Cairo 1996.

12. Tsagalis G. Renal anemia: A nephrologist's view. Hippokratia.2011; 15: pp39-43.

13. Vivante A, \&Hildebrandt F. Exploring the genetic basis of early-onset chronic kidney disease. Nat Rev Nephrol 2016; 12: pp133146.

14. Feroze U, Martin D, Kalantar-Zadeh K, Kim JC, Reina-Patton A, and Kopple JD. Anxiety and depression in maintenance dialysis patients: preliminary data of a cross-sectional study and brief literature review. J Ren Nutr 2012; 22: pp207-210.

15. Abdel Salam MM, Abdo MA, Yousef UM, and Mohamed SA. Assessment of depression and anxiety in children on regular hemodialysis. Egypt J Psychiatr 2014; 35: pp100-4.

16. Cukor D, Rosenthal DS, Jindal RM, Brown $\mathrm{CD}$, and Kimmel PI. Depression is an important contributor to low medication adherence in hemodialyzed patients and transplant recipients. Kidney Int 2009, 75: pp1223-1229.

17. Shafi, S. T., and Shafi, T. A comparison of anxiety and depression between pre-dialysis chronic kidney disease patients and hemodialysis patients using hospital anxiety and depression scale. Pakistan Journal of Medical Sciences2017; 33(4): pp876-880.

18. Ng HJ, Tan WJ, Mooppil N, et al. Prevalence and patterns of depression and anxiety in hemodialysis patients: a 12-month prospective study on incident and prevalent populations. Br J Health Psychol 2015; 20(2):pp374-395.

19. Sullivan PF, Neale MC, Kendler KS. Genetic epidemiology of major depression: 
review and meta analysis. Am J Psychiatry 2000; 157: pp1552-1562.

20. Hsu HJ, Yen CH, Chen CK, Wu IW, Lee $\mathrm{CC}$, Sun CY .Association between uremic toxins and depression in patients with chronic kidney disease undergoing maintenance hemodialysis. Gen Hosp Psychiatry 2013. 35: pp 23-27.

21. Ahlawat R, Tiwari P, D'Cruz S. Prevalence of depression and its associated factors among patients of chronic kidney disease in a public tertiary care hospital in India: A crosssectional study. Saudi J Kidney Dis Transpl 2018; 29: pp1165-73.

22. Nomani AZ, Iqbal $M$, Bacha $F$,et al. Demographic profile and associations of dialysis dependent chronic kidney disease patients in federal capital of pakistan. Pak J Neurol Sci 2016; 11(1): pp14-19.

23. Tanvir S, Butt G-D, and Taj R. Prevalence of Depression and Anxiety in Chronic Kidney Disease Patients on Haemodialysis. Ann Pak Inst Med Sci 2013 ; 9(2): pp 64-67.

24. Makara-Studzińska M \&Koslak A. Depression symptoms among patients with end stage renal disease and among primary health care patients. Arch Psychiatry Psychother 2011; 3: pp5-10.

25. Bossola M, Ciciarelli C, Di Stasio E, et al. Correlates of symptoms of depression and

\section{Statements}

\section{Ethical approval and consent}

Approval of the study by an ethical committee of Benha University, AlMonufia University, Alzagazig University and $6^{\text {th }}$ of October hospital were obtained and informed written consent was obtained from the parents before enrollment in the study.

\section{Consents for publication}

The contents and material of the manuscript have not been previously reported at any length or being considered for publishing elsewhere.

Availability of data and material

"Not applicable" anxiety in chronic hemodialysis patients. Gen Hosp Psychiatry 2010; 32: pp125-31.

26. Lee YJ, Kim MS, Cho S, et al. Association of depression and anxiety with reduced quality of life in patients with predialysis chronic kidney disease. Int J Clin Pract 2013; 67: pp363-8.

27. Macaron G, Fahed M, Matar D, et al. Anxiety, depression and suicidal ideation in Lebanese patients undergoing hemodialysis. Community Ment Health J 2014; 50: pp235-8.

28. Roozbeh J, Sharifian M, Ghanizadeh A, Sahraian A, Sagheb MM, and Shabani S. Association of zinc deficiency and depression in the patients with end-stage renal disease no hemodialysis. J Ren Nutr 2011, 21:pp184-187. 29. Dziubek, W., Kowalska, J., Kusztal, M., Rogowski, Ł., Gołębiowski, T., Nikifur, M., Woźniewski, M. The Level of Anxiety and Depression in Dialysis Patients Undertaking Regular Physical Exercise Training - a Preliminary Study. Kidney and Blood Pressure Research 2016, 41(1), pp86-98.

30. El Filali A, Bentata Y, Ada N, Oneib B. Depression and anxiety disorders in chronic hemodialysis patients and their quality of life: A cross-sectional study about 106 cases in the northeast of morocco. Saudi J Kidney Dis Transpl 2017; 28: pp341-8.

\section{Conflict of interest}

The authors declare no conflict of interest.

\section{Funding}

The authors declare that the research is selffunded by the authors

\section{Acknowledgements}

Authors would like to thank all patients and their family members for their valuable contributions to the study.

$\begin{array}{ll}\text { Submission date } & 15 / 08 / 2020 \\ \text { Acceptance date } & 12 / 10 / 2020 \\ \text { Published online } & 31 / 12 / 2020\end{array}$

